Case Report

\title{
Coagulopathy and Extremely Elevated PT/INR after Dabigatran Etexilate Use in a Patient with End-Stage Renal Disease
}

\author{
Joonseok Kim, Mrinal Yadava, In Chul An, Abrar Sayeed, \\ Heather S. Laird-Fick, Venu Gourineni, and George S. Abela \\ Department of Medicine, Michigan State University, East Lansing, MI 48824, USA \\ Correspondence should be addressed to Joonseok Kim; joonseok.kim@hc.msu.edu
}

Received 27 April 2013; Revised 10 July 2013; Accepted 22 August 2013

Academic Editor: Dieter Horstkotte

Copyright (C) 2013 Joonseok Kim et al. This is an open access article distributed under the Creative Commons Attribution License, which permits unrestricted use, distribution, and reproduction in any medium, provided the original work is properly cited.

\begin{abstract}
Introduction. Dabigatran is an oral direct thrombin inhibitor which has been approved for prophylaxis of stroke in patients with atrial fibrillation. The use of dabigatran etexilate increased rapidly due to many benefits. However, questions have been raised constantly regarding the safety of dabigatran etexilate. Case. A 58-year-old Caucasian male with a history of recurrent paroxysmal atrial fibrillation status after pacemaker and end-stage renal disease on hemodialysis came to the Emergency Department with the complaint of severe epistaxis. He had been started on dabigatran $150 \mathrm{mg}$ twice a day about 4 months ago as an outpatient by his cardiologist. His prothrombin time (PT) was 63 seconds with international normalized ratio (INR) of 8.8 and his activated partial thromboplastin time (aPTT) was 105.7 seconds. Otherwise, all labs were unremarkable including the liver function test. Dabigatran was stopped immediately. His INR and aPTT trended downward, reaching normal levels 5 days after admission. Conclusion. Dabigatran is contraindicated in patients with severe kidney insufficiency as it is predominantly excreted via the kidney ( 80\%). Elderly patients over 75 and patients with chronic renal impairment should be carefully evaluated before starting dabigatran. Despite studies showing only mild increase in aPTT and PT/INR in patients receiving dabigatran, close monitoring may be reasonable in patients with renal insufficiency.
\end{abstract}

\section{Introduction}

Dabigatran etexilate is a novel oral anticoagulant approved by the Food and Drug Administration (FDA) for stroke prophylaxis in patients with nonvalvular atrial fibrillation (AF). Since approval, the use of dabigatran etexilate has increased substantially. Nearly 17 percent of patients with nonvalvular AF were started on dabigatran etexilate within just one year of approval [1]. A recent study showed that approximately 725,000 patients in the United States have been on dabigatran etexilate [1]. However, questions have been raised consistently regarding the safety of dabigatran etexilate. Here, we present a case of dabigatran etexilate-induced coagulopathy with extremely increased PT/INR in a patient with end-stage renal disease (ESRD).

\section{Case Presentation}

A 58-year old Caucasian male with a history of recurrent paroxysmal AF came to the Emergency Department (ED) with the complaint of epistaxis. He had a history of end stage renal disease (ESRD) on hemodialysis. His cardiologist had started him on dabigatran etexilate $150 \mathrm{mg}$ twice a day about 4 months ago. He was previously on warfarin, but side effects including multiple episodes of minor epistaxis and gastrointestinal bleeds requiring transfusions warranted the switch to dabigatran etexilate. His CHADS2 score was 5 , supporting the need for anticoagulation to prevent future stroke events [2]. Since being started on dabigatran etexilate, he has been tolerating it except for minor epistaxis. On the day of ED presentation, the patient awoke to find himself in a pool of blood. His vital signs were unremarkable on arrival to the hospital. Because of persistent epistaxis, an inflatable balloon epistaxis device was placed in the right nostril in the $\mathrm{ED}$, with good hemostasis. He was admitted to the hospital for monitoring and further work-up.

Abnormal labs at the time of admission included a prothrombin time (PT) of 63 seconds, INR of 8.8 , activated partial thromboplastin time (aPTT) of 105.7 seconds, and elevated BUN and creatinine of $73 \mathrm{mg} / \mathrm{dL}$ and $4.12 \mathrm{mg} / \mathrm{dL}$, 
respectively. His hemoglobin and hematocrit were frequently checked, and they remained stable around $12 \mathrm{mg} / \mathrm{dL}$ and $37 \mathrm{mg} / \mathrm{dL}$, respectively, not requiring any pRBC transfusions. The patient had not missed any dialysis session prior to admission. The supratherapeutic INR was thought to be secondary to dabigatran etexilate, and the medication was held. Other possible causes of supratherapeutic INR were excluded, including Vitamin K deficiency and severe liver disease, as laboratory values showed normal liver function test (LFT), albumin, and Vitamin K levels. He was given fresh frozen plasma (FFP), and ENT was consulted for additional packing. As dabigatran etexilate was a new anticoagulation agent at the time, the hospital did not have a reversal protocol for dabigatran etexilate toxicity in place and thus FFP was used. He remained stable clinically and the INR and aPTT trended downward after holding the dabigatran and continuing his scheduled dialysis session the following day. INR was 1.7 at the time of discharge and his aPTT had normalized. After a 5-day hospital stay, he was discharged. He went home without anticoagulants as his recurrent bleeds were thought to be a substantial morbidity risk outweighing the benefit of stroke prevention.

\section{Discussion}

Oral anticoagulation is an important part of long-term AF management to prevent embolic stroke and other systemic thromboembolic diseases. For decades, warfarin or oral Vitamin $\mathrm{K}$ antagonists were the main anticoagulants used. However, with the narrow therapeutic index and multiple drug and food interactions associated with warfarin, an alternative was needed. Dabigatran etexilate was the first novel oral anticoagulant approved by the FDA for stroke prophylaxis in nonvalvular AF [8]. Since its approval, dabigatran use increased substantially. Nevertheless, concern about its safety has been raised consistently.

Dabigatran etexilate is absorbed across the gastrointestinal (GI) wall by p-glycoprotein [9] and consequently converted by esterases to dabigatran, an active from of dabigatran etexilate [9]. The bioavailability of dabigatran is low (6-7\%) compared to other Xa inhibitors. However, its plasma concentration peaks in 1.25-1.5 hours, which allows for a more rapid onset of action compared to Vitamin K antagonists (VKA) [10]. The half-life of dabigatran etexilate in patients without renal impairment is 14 to 17 hours [11], and as it is primarily excreted by the kidney (80\%), dosage reductions are necessary for those who have renal impairment [11].

Dabigatran etexilate has many advantages when compared to oral VKAs. One of the major benefits of dabigatran etexilate is its predictable pharmacokinetic profile [11]. The absorption of dabigatran etexilate is constant, with less interindividual variability [12], and this unique characteristic prevents frequent laboratory monitoring [10]. Furthermore, dabigatran etexilate is not converted by the cytochrome P450 enzyme, thereby reducing drug interactions [10]. Due to its rapid onset of action, bridging with unfractionated or low molecular weight heparin is not needed, which decreases considerable burden on the patient and health care.
However, there are some concerns associated with using dabigatran etexilate. One major concern is the absence of an antidote to reverse its action. The bleeding rate associated with dabigatran etexilate is not higher than that of VKAbased on clinical trials and postmarket assessment by the FDA $[12,13]$. Nevertheless, bleeding is still a serious, potentially life-threatening complication. Dabigatran etexilate was suspected to be the main culprit behind the deaths of 542 patients in 2011 [14, 15]. In the case of a severe, clinically significant bleeding, dabigatran etexilate has to be stopped immediately. Dialysis should be considered in the case of an active, potentially fatal bleeding [16].

Patients with renal impairment have an increased risk of bleeding when taking dabigatran etexilate. More than $80 \%$ of absorbed dabigatran etexilate is excreted by the kidney $[11,17]$. Thus a reduced dose is required for patients who have renal impairment. The FDA has approved a $75 \mathrm{mg}$ twice daily dose of dabigatran etexilate for patients with a creatinine clearance of $15-30 \mathrm{~mL} / \mathrm{min}$ [13]. In the United States, dabigatran etexilate is not indicated if creatinine clearance is less than $15 \mathrm{~mL} / \mathrm{min}$ in patients with acute renal failure or ESRD. However, there are no outcome data for the newer anticoagulants in patients with creatinine clearance less than $30 \mathrm{~mL} / \mathrm{min}$, and the current European Society of Cardiology (ESC) guidelines advise against their use in this patient population [18]. However, because dabigatran etexilate is mainly prescribed by primary care physicians and cardiologists, not all patients' renal functions are assessed properly before starting dabigatran etexilate, as we could see in our case.

Another concern of dabigatran etexilate is the difficulty of assessing its anticoagulant effect. It is important to determine the anticoagulant effect in the cases of acute, life-threatening bleeding, preoperative evaluation, and suspected overdose [19]. The thrombin clotting time (TCT) is a sensitive test for dabigatran etexilate, but it is not useful for monitoring patients with possible dabigatran etexilate-induced coagulopathy because it is too sensitive. The Ecarin clotting time (ECT) is also a sensitive test and may have a dose-related response, but it is not available as a routine coagulation test and has not been approved by the FDA for monitoring the activity of dabigatran etexilate [20]. Some studies indicate that if a patient on dabigatran has an aPTT $>90$ seconds and INR $>2$, one must consider overdosing or dabigatran accumulation [21]. However, most studies have found PT and aPTT to be insensitive to therapeutic doses of dabigatran etexilate, since they do not have a linear relationship [16]. Currently, there is no available laboratory study to confirm dabigatran etexilate-induced coagulopathy in the hospital setting [20].

This case demonstrates a dabigatran-induced coagulopathy with very high PT/INR. Dabigatran should be avoided in patients with severe renal insufficiency and ESRD on hemodialysis. In our case, the patient had a significant epistaxis with increased PT/INR, and the bleeding was controlled only after nasal packing and administration of one unit of FFP. PT/INR and aPTT decreased consequently after holding the dabigatran as well as continuing his scheduled dialysis. Studies suggest that increased INR is not correlated to the activity of dabigatran, but as of yet there is no sufficient data 
TABLE 1: Reported cases of dabigatran overdose.

\begin{tabular}{|c|c|c|c|c|c|c|c|c|}
\hline Authors & Year & Age/sex & $\begin{array}{l}\text { Dabigatran } \\
\text { dose }\end{array}$ & $\begin{array}{c}\text { Reason for } \\
\text { anticoagulation }\end{array}$ & Comorbidities & Complication & $\begin{array}{l}\text { Attempted } \\
\text { reversal (other } \\
\text { than holding } \\
\text { dabigatran) }\end{array}$ & Outcome \\
\hline Chen et al. [3] & 2013 & $80 / \mathrm{M}$ & $\begin{array}{l}150 \text { mg orally } \\
\text { once a day }\end{array}$ & $\begin{array}{c}\text { Atrial } \\
\text { fibrillation }\end{array}$ & $\begin{array}{c}\text { CKD stage } 3, \\
\text { hypothyroidism }\end{array}$ & Hemoptysis & FFP, HD & $\begin{array}{l}\text { Bleeding ceased } \\
\text { with HD }\end{array}$ \\
\hline $\begin{array}{l}\text { Fountzilas et al. } \\
{[4]}\end{array}$ & 2013 & $82 / \mathrm{F}$ & $\begin{array}{l}150 \mathrm{mg} \text { orally } \\
\text { twice a day }\end{array}$ & $\begin{array}{c}\text { Atrial } \\
\text { fibrillation }\end{array}$ & $\begin{array}{l}\text { CHF, CAD, } \\
\text { HTN, AKI }\end{array}$ & 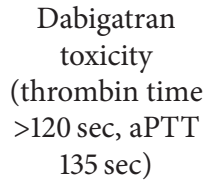 & & Toxicity resolved \\
\hline $\begin{array}{l}\text { Lal and Van } \\
\text { Heukelom [5] }\end{array}$ & 2012 & $81 / \mathrm{F}$ & $\begin{array}{l}150 \mathrm{mg} \text { orally } \\
\text { once a day }\end{array}$ & $\begin{array}{c}\text { Atrial } \\
\text { fibrillation }\end{array}$ & $\begin{array}{c}\text { DM, CKD stage } \\
\text { 3, HTN }\end{array}$ & $\begin{array}{l}\text { Surgical site } \\
\text { hematoma }\end{array}$ & FFP, vitamin $\mathrm{K}$ & $\begin{array}{l}\text { No further } \\
\text { bleeding after } \\
\text { hematoma } \\
\text { evacuation }\end{array}$ \\
\hline $\begin{array}{l}\text { Lal and Van } \\
\text { Heukelom [5] }\end{array}$ & 2012 & $76 / \mathrm{M}$ & $\begin{array}{l}150 \text { mg orally } \\
\text { twice a day }\end{array}$ & Atrial flutter & $\begin{array}{l}\text { CAD, CHF, } \\
\text { HTN }\end{array}$ & $\begin{array}{c}\text { Colonic } \\
\text { anastomosis } \\
\text { site bleed }\end{array}$ & & $\begin{array}{l}\text { No further } \\
\text { bleeding }\end{array}$ \\
\hline $\begin{array}{l}\text { Lal and Van } \\
\text { Heukelom [5] }\end{array}$ & 2012 & $64 / F$ & Unknown & $\begin{array}{c}\text { Atrial } \\
\text { fibrillation }\end{array}$ & $\begin{array}{l}\text { CAD, Diastolic } \\
\text { CHF, CVA, AKI }\end{array}$ & $\begin{array}{l}\text { GI bleed, } \\
\text { subclavian } \\
\text { catheter } \\
\text { insertion site } \\
\text { bleed, SAH }\end{array}$ & $\begin{array}{c}\text { FFP, } \\
\text { desmopressin, } \\
\text { vitamin } \mathrm{K}, \\
\text { apheresis platelet } \\
\text { concentrate, HD }\end{array}$ & $\begin{array}{l}\text { Bleeding stopped, } \\
\text { however patient } \\
\text { made comfort } \\
\text { care due to } \\
\text { pneumonia and } \\
\text { multiple } \\
\text { comorbidities }\end{array}$ \\
\hline $\begin{array}{l}\text { Lal and Van } \\
\text { Heukelom [5] }\end{array}$ & 2012 & $80 / \mathrm{F}$ & $\begin{array}{l}150 \text { mg orally } \\
\text { twice a day }\end{array}$ & $\begin{array}{c}\text { Atrial } \\
\text { fibrillation }\end{array}$ & $\begin{array}{c}\text { CKD stage } 3, \\
\text { HTN }\end{array}$ & $\begin{array}{l}\text { SAH, subdural } \\
\text { hemorrhages, } \\
\text { intragluteal } \\
\text { hemorrhage }\end{array}$ & FFP, HD & $\begin{array}{l}\text { Patient made } \\
\text { comfort care }\end{array}$ \\
\hline Chang et al. [6] & 2013 & $94 / \mathrm{M}$ & $\begin{array}{l}150 \text { mg orally } \\
\text { twice a day }\end{array}$ & $\begin{array}{l}\text { Atrial } \\
\text { fibrillation }\end{array}$ & & $\begin{array}{l}\text { Fall with large } \\
\text { subdural } \\
\text { hematoma } \\
\text { compressing } \\
\text { the right lateral } \\
\text { ventricle }\end{array}$ & $\begin{array}{c}\text { Factor VIII } \\
\text { inhibitor (FEIBA; } \\
\text { Baxter Healthcare } \\
\text { Corporation), HD }\end{array}$ & $\begin{array}{c}\text { Clinical } \\
\text { improvement } \\
\text { with subsequent } \\
\text { discharge to a } \\
\text { rehabilitation } \\
\text { facility }\end{array}$ \\
\hline $\begin{array}{l}\text { Maddry et al. } \\
\text { [7] }\end{array}$ & 2013 & $74 / \mathrm{M}$ & $\begin{array}{l}150 \text { mg orally } \\
\text { twice a day }\end{array}$ & $\begin{array}{c}\text { Atrial } \\
\text { fibrillation }\end{array}$ & AKI & GI bleed & $\begin{array}{c}\text { FFP, prothrombin } \\
\text { complex } \\
\text { concentrate, } \\
\text { recombinant } \\
\text { factor VIIa, HD }\end{array}$ & $\begin{array}{l}\text { Patient died due } \\
\text { to sepsis and DIC }\end{array}$ \\
\hline
\end{tabular}

CHF: congestive heart failure; CAD: coronary artery disease; HTN: hypertension; DM: diabetes mellitus; AKI: acute kidney injury; CKD: chronic kidney disease; CVA: cerebrovascular attack; FFP: frozen fresh plasma; HD: hemodialysis; DIC: disseminated intravascular coagulation.

to clarify the relationship of PT/INR in patients on dabigatran and their risk of bleeding.

\section{Conclusion}

There have been multiple reported cases of bleeding related to dabigatran use (Table 1). However, to the best of our knowledge, this is the first report of an extremely elevated PT/INR with the use of dabigatran in a patient with ESRD. The current guideline indicates that routine PT/INR followup is not necessary for patients taking dabigatran. However, since there is no reliable laboratory study to monitor the anticoagulant effect of dabigatran, it may be beneficial to check the coagulation panel, including PT and aPTT, to reduce the risk of bleeding in patients especially at high risk for bleeding. It is also imperative that patients have their renal function checked prior to starting therapy and that the drug is dosed based on creatinine clearance. Warfarin should be regarded as an option in populations with decreased renal function to decrease the risk of bleeding and increase its control in case of bleeding. Studies are warranted to find a safe dose of dabigatran in patients with renal impairment and develop a better way of monitoring the activity of dabigatran.

\section{References}

[1] K. Kirley, D. M. Qato, R. Kornfield, R. S. Stafford, and G. C. Alexander, "National trends in oral anticoagulant use in the United States, 2007 to 2011," Circ Cardiovasc Qual Outcomes, vol. 5, pp. 615-621, 2012. 
[2] B. F. Gage, C. Van Walraven, L. Pearce et al., "Selecting patients with atrial fibrillation for anticoagulation: stroke risk stratification in patients taking aspirin," Circulation, vol. 110, no. 16, pp. 2287-2292, 2004.

[3] B. C. Chen, N. R. Sheth, K. A. Dadzie et al., "Hemodialysis for the treatment of pulmonary hemorrhage from dabigatran overdose," American Journal of Kidney Diseases, vol. 62, no. 3, pp. 591-594, 2013.

[4] C. Fountzilas, J. George, and R. Levine, "Dabigatran overdose secondary to acute kidney injury and amiodarone use," The New Zealand Medical Journal, vol. 126, pp. 110-112, 2013.

[5] Y. Lal and J. Van Heukelom, "Dabigatran: a cause of hematologic emergency," The American Journal of the Medical Sciences, vol. 364, no. 3, pp. 190-193, 2012.

[6] D. N. Chang, W. E. Dager, and A. I. Chin, "Removal of dabigatran by hemodialysis," American Journal of Kidney Diseases, vol. 61, pp. 487-489, 2013.

[7] J. K. Maddry, M. K. Amir, D. Sessions, and K. Heard, "Fatal dabigatran toxicity secondary to acute renal failure," American Journal of Emergency Medicine, vol. 31, no. 2, pp. 462.e1-462.e2, 2013.

[8] B. Hughes, "First oral warfarin alternative approved in the US," Nature Reviews Drug Discovery, vol. 9, no. 12, pp. 903-906, 2010.

[9] S. Schulman and A. Majeed, "The oral thrombin inhibitor dabigatran: strengths and weaknesses," Seminars in Thrombosis and Hemostasis, vol. 38, no. 1, pp. 7-15, 2012.

[10] J. Stangier, "Clinical pharmacokinetics and pharmacodynamics of the oral direct thrombin inhibitor dabigatran etexilate," Clinical Pharmacokinetics, vol. 47, no. 5, pp. 285-295, 2008.

[11] J. Stangier, K. Rathgen, H. Stähle, D. Gansser, and W. Roth, "The pharmacokinetics, pharmacodynamics and tolerability of dabigatran etexilate, a new oral direct thrombin inhibitor, in healthy male subjects," British Journal of Clinical Pharmacology, vol. 64, no. 3, pp. 292-303, 2007.

[12] J. W. Eikelboom, L. Wallentin, S. J. Connolly et al., "Risk of bleeding with 2 doses of dabigatran compared with warfarin in older and younger patients with atrial fibrillation: an analysis of the randomized evaluation of long-term anticoagulant therapy (RE-LY) Trial," Circulation, vol. 123, no. 21, pp. 2363-2372, 2011.

[13] "FDA drug safety communication: update on the risk for serious bleeding events with the anticoagulant Pradaxa," 2012.

[14] J. van Ryn, T. Litzenburger, K. Waterman et al., "Dabigatran anticoagulant activity is neutralized by an antibody selective to dabigatran," in Proceedings of the American College of Cardiologists Annual Conference.

[15] FDA Monitoring MedWatch Reports, "Anticoagulants the Leading Reported Drug Risk in 2011 May 31, 2012," New Data from 2011 Quarters 3-4, 2012.

[16] J. Van Ryn, J. Stangier, S. Haertter et al., "Dabigatran etexilate-a novel, reversible, oral direct thrombin inhibitor: Interpretation of coagulation assays and reversal of anticoagulant activity," Thrombosis and Haemostasis, vol. 103, no. 6, pp. 1116-1127, 2010.

[17] J. Harenberg, C. Giese, S. Marx, and R. Krämer, "Determination of dabigatran in human plasma samples," Seminars in Thrombosis and Hemostasis, vol. 38, no. 1, pp. 16-22, 2012.

[18] H. Heidbuchel, P. Verhamme, M. Alings et al., "EHRA Practical Guide on the use of new oral anticoagulants in patients with non-valvular atrial fibrillation: executive summary," European Heart Journal, 2013.

[19] J. Van Ryn, L. Baruch, and A. Clemens, "Interpretation of point-of-care INR results in patients treated with dabigatran," American Journal of Medicine, vol. 125, no. 4, pp. 417-420, 2012.
[20] L. Kernan, S. Ito, F. Shirazi, and K. Boesen, "Fatal gastrointestinal hemorrhage after a single dose of dabigatran," Clinical Toxicology, vol. 50, pp. 571-573, 2012.

[21] T. L. Lindahl, F. Baghaei, I. F. Blixter et al., "Effects of the oral, direct thrombin inhibitor dabigatran on five common coagulation assays," Thrombosis and Haemostasis, vol. 105, no. 2, pp. 371-378, 2011. 


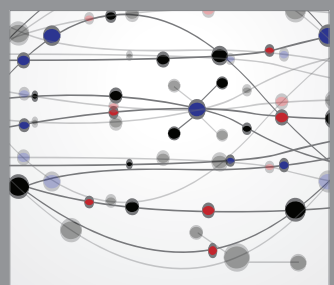

The Scientific World Journal
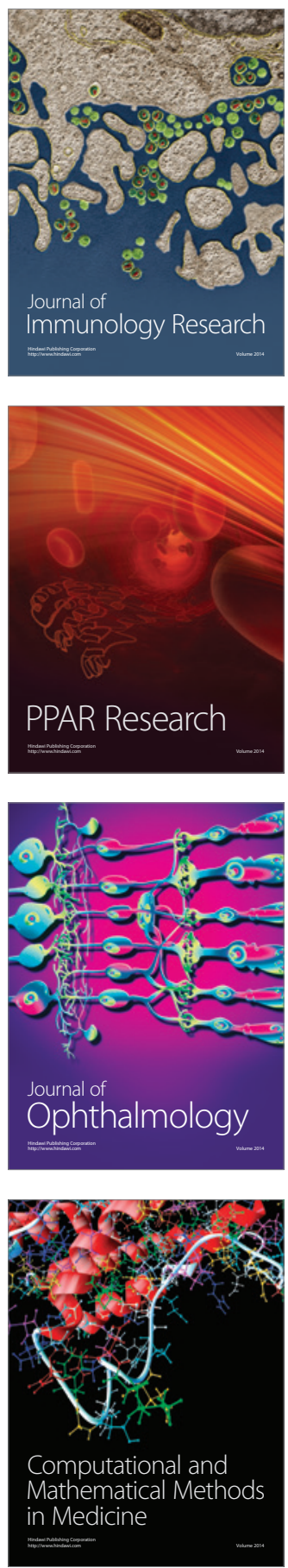

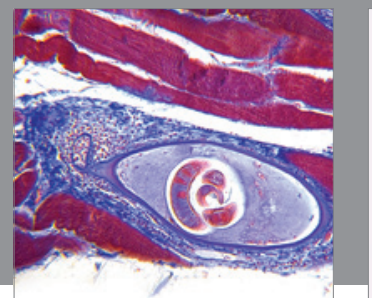

Gastroenterology

Research and Practice
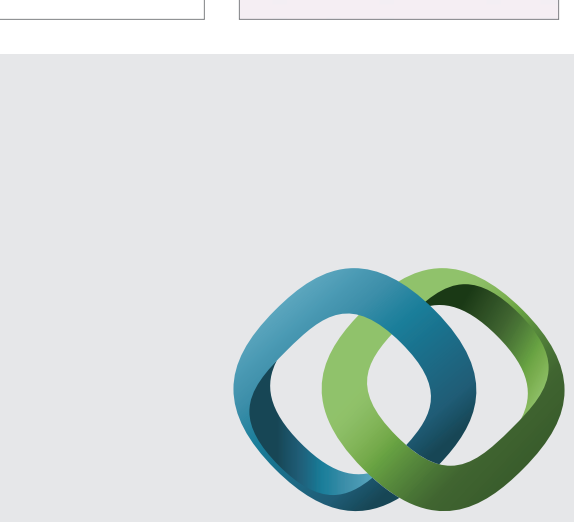

\section{Hindawi}

Submit your manuscripts at

http://www.hindawi.com
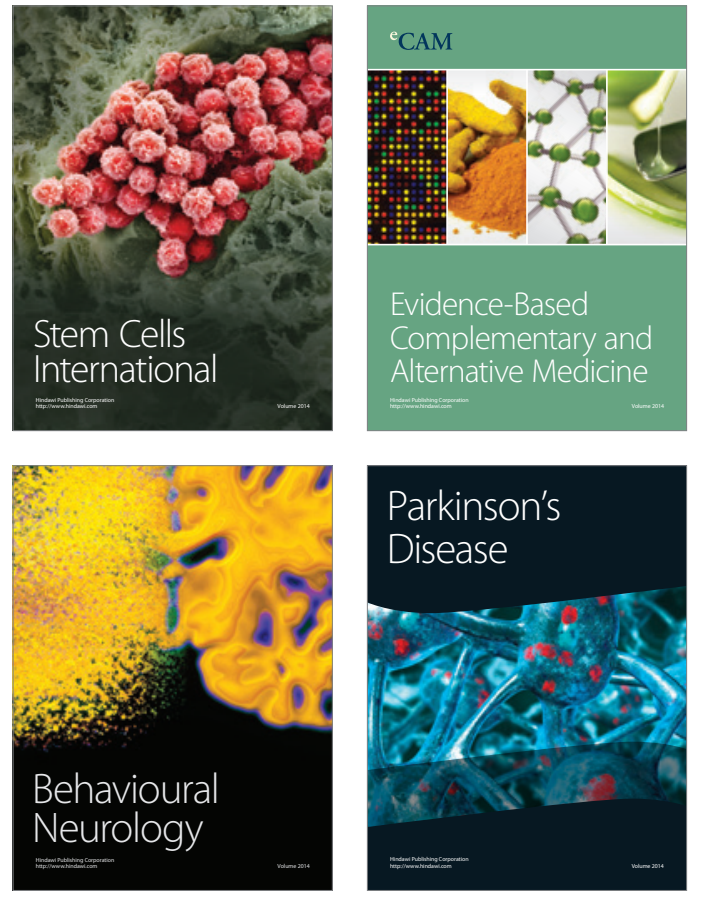
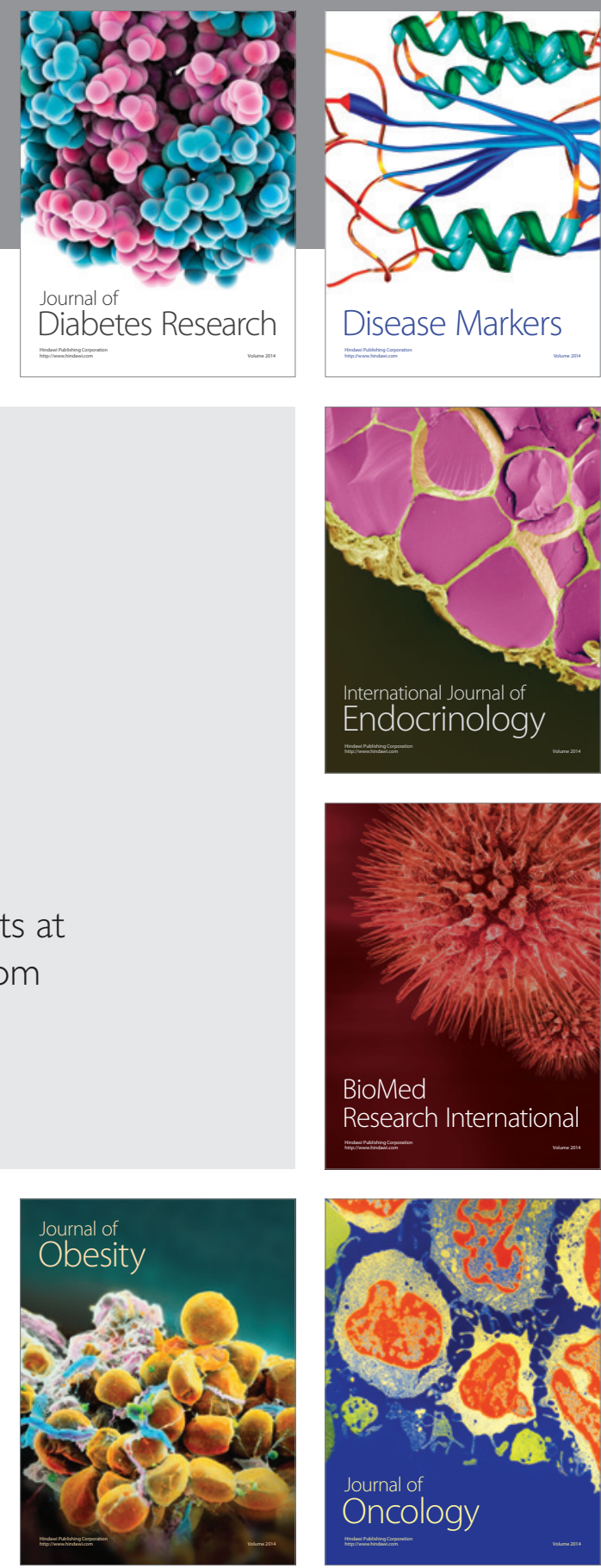

Disease Markers
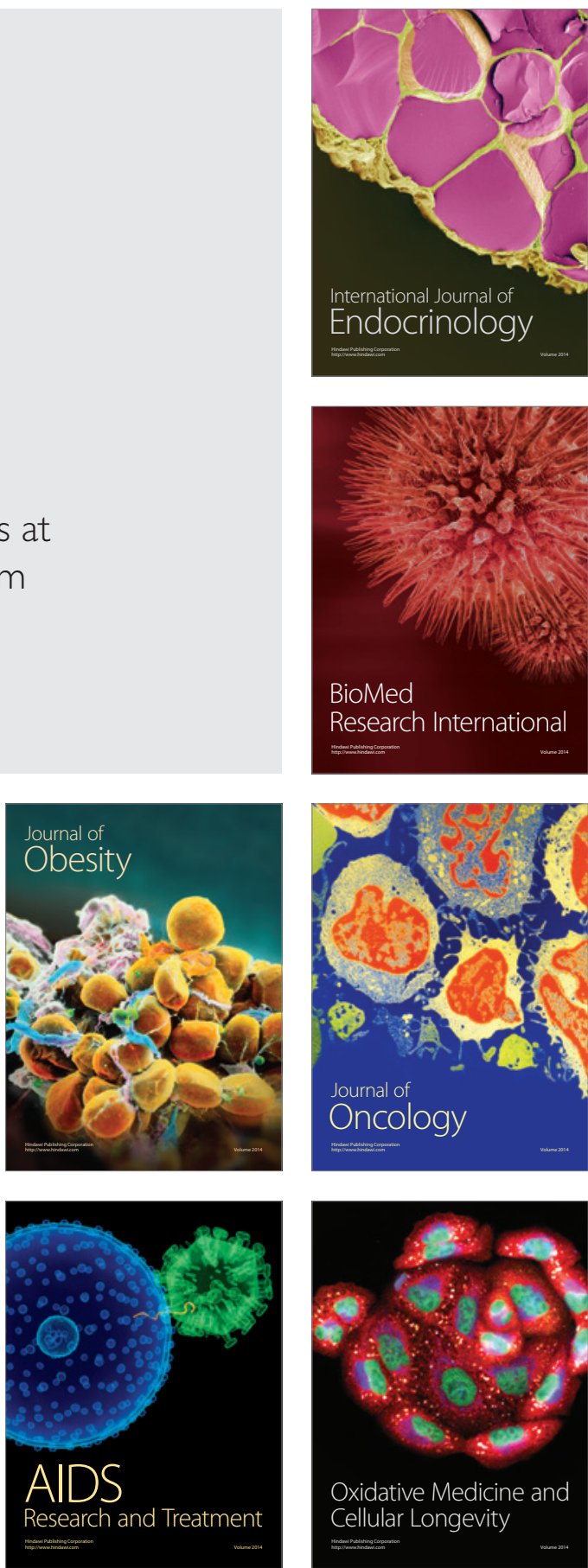